J Am Chem Soc. 2019 February 06; 141(5): 1998-2011. doi:10.1021/jacs.8b10990.

\title{
A Solid-State NMR and MD Study of the Structure of the Statherin Mutant SNa15 on Mineral Surfaces
}

\author{
Erika L. Buckle ${ }^{1,+}$, Arushi Prakash ${ }^{2,+}$, Massimiliano Bonomi $^{3}$, Janani Sampath ${ }^{2}$, Jim $^{2}$ \\ Pfaendtner ${ }^{2,}{ }^{*}$, Gary P. Drobny ${ }^{1,}{ }^{*}$ \\ ${ }^{1}$ Department of Chemistry, University of Washington, Box 351700, Seattle, Washington 98195, \\ United States \\ ${ }^{2}$ Department of Chemical Engineering, University of Washington, Seattle, Washington 98195, \\ United States \\ ${ }^{3}$ Structural Bioinformatics Unit, Institut Pasteur, CNRS UMR 3528, 75015 Paris, France
}

\begin{abstract}
Elucidation of the structure and interactions of proteins at native mineral interfaces is key to understanding how biological systems regulate the formation of hard tissue structures. In addition, understanding how these same proteins interact with non-native mineral surfaces has important implications for the design of medical and dental implants, chromatographic supports, diagnostic tools, and a host of other applications. Here, we combine solid-state NMR spectroscopy, isotherm measurements, and molecular dynamics simulations to study how SNa15, a peptide derived from the hydroxyapatite (HAP) recognition domain of the biomineralization protein statherin, interacts with HAP, silica $\left(\mathrm{SiO}_{2}\right)$ and titania $\left(\mathrm{TiO}_{2}\right)$ mineral surfaces. Adsorption isotherms are used to characterize the binding affinity of $\mathrm{SNa} 15$ to $\mathrm{HAP}, \mathrm{SiO}_{2}$, and $\mathrm{TiO}_{2}$. We also apply $1 \mathrm{D}^{13} \mathrm{C} \mathrm{CP}$ MAS, $1 D^{15} \mathrm{~N}$ CP MAS, and 2D ${ }^{13} \mathrm{C}-{ }^{13} \mathrm{C}$ DARR experiments to SNa15 samples with uniformly ${ }^{13} \mathrm{C}$ - and ${ }^{15} \mathrm{~N}$ - enriched residues to determine backbone and side-chain chemical shifts. Different computational tools, namely TALOS-N and molecular dynamics simulations, are used to deduce secondary structure from backbone and side-chain chemical shift data. Our results show that SNa15 adopts an a-helical conformation when adsorbed to $\mathrm{HAP}$ and $\mathrm{TiO}_{2}$, but the helix largely unravels upon adsorption to $\mathrm{SiO}_{2}$. Interactions with $\mathrm{HAP}$ are mediated in general by acidic and some basic amino acids, although the specific amino acids involved in direct surface interaction vary with surface. The integrated experimental and computational approach used in this study is able to provide high-resolution insights into adsorption of proteins on interfaces.
\end{abstract}

\section{INTRODUCTION}

Several organisms produce hard structures such as bone, teeth, shells, and exoskeletons from inorganic materials (i.e. calcite, silica, and hydroxyapatite) through a process known as biomineralization. These organisms use specialized proteins that interact with these inorganic materials thereby accelerating ${ }^{1}$ or inhibiting ${ }^{2,3}$ the growth of mineral solids, or

\footnotetext{
*Correspondence: drobny@chem.washington.edu,jpfaendt@uw.edu.

${ }^{+}$Authors contributed equally to this work
} 
even altering mineral morphology. ${ }^{4-10}$ Detailed atomic-level insight of how of proteins interact with these minerals is required to better understand the role that proteins play in biomineralization and to thereafter exploit it for materials synthesis. This requires the resolution of the secondary and tertiary structure of proteins adsorbed on surfaces, the identification of both the residues that are crucial for protein-surface interaction and the nature of protein-surface interactions.

To date, only a handful of experimentally confirmed structural models of proteins interacting with their native mineral surfaces have been reported. ${ }^{11-18}$ These protein-surface systems include either small extracellular matrix (ECM) proteins or ECM protein domains that are adsorbed onto hydroxyapatite (HAP) crystals. ${ }^{14,19-29}$ These studies suggest that protein secondary structure can change when adsorbed to surfaces. They also hypothesize that the interaction of amino acid side-chains with inorganic surfaces are dependent on the secondary structures of adsorbed proteins. ${ }^{20,22,24,25,27,30}$ Thus, all components of protein-surface interaction can be determined only when the structure of the adsorbed protein is resolved.

Salivary statherin is a 43-residue ECM protein (DpSpSEEKFLRRIGRFGYGYGPYQPVPEQPLYPQPYQPQYQQYTF) that regulates HAP nucleation at enamel surfaces. The structure of statherin adsorbed onto HAP has been resolved. ${ }^{29,31-33}$ Statherin has been studied by calorimetric methods ${ }^{12,25}$, adsorption isotherms, ${ }^{31,34}$ solution NMR, ${ }^{35,36}$ solid-state NMR (ssNMR), ${ }^{19-21,23,24,26,27,29,32,33,37,38}$ and circular dichroism. ${ }^{31,39}$ These studies indicate that statherin is unstructured in solution but structures when adsorbed onto HAP surfaces. Notably, the 15-residue long N-terminus adopts a distorted $\mathrm{a}$-helical conformation and the $\mathrm{C}$-terminus also becomes partly helical upon adsorption to HAP. ${ }^{33,40,41}$

These studies also identify specific residues in statherin that interact with HAP. For example, acidic side-chains exhibit strong affinity for calcium phosphate surfaces. ${ }^{31}$ Consequently, the $\mathrm{N}$-terminus of statherin, which containing acidic residues like phosphoserine (pS), aspartic acid (D), and glutamic acid (E), has been shown to be essential for HAP binding. ${ }^{31}$ Similarly, the interaction of basic residues with HAP have also been studied. When Goobes et al. mutated selected basic residues to alanine, the protein displayed lower the binding affinity to the surface but did not affect the surface coverage or the adsorption enthalpy. ${ }^{29} \mathrm{In}$ contrast, when all the basic residues (K6, R9, R10, and R13) were replaced with alanine, there was a significant change in the adsorption enthalpy and surface coverage. Therefore, they hypothesized that the nature of basic residues is not as important to binding as the presence of a number of basic residues. ${ }^{29}$ In contrast to acidic and basic residues, the role of non-polar residues in protein-surface interactions is less clear. The HAP-binding domain of statherin has four types of nonpolar residues (L, I, G, and F) but only F14 was found to be in proximity with the HAP surface. ${ }^{20,23}$

There are limited studies that model the interaction of statherin and HAP. Notably, Rosetta and RosettaSurface modeling programs have been used for this. ${ }^{22,32,42}$ However, these allatom models of the protein include simplifying assumptions that make calculations faster, like freezing the surface, restraining the protein backbone, and not accounting for waters and ions. Thus, they might exclude important interactions that affect protein structures. MD 
simulations, which can explicitly model the surface, protein, and solvent, include these interactions. In fact, recent advances in the use of advanced MD-based simulation methods like metadynamics ${ }^{43,44}$ have been shown to be highly effective in simulating the structure and binding of peptides at surfaces ${ }^{45}$. Furthermore, owing to the ease with which NMR chemical shifts can be directly estimated from classical simulations, ${ }^{46,47}$ the metadynamic metainference approach ${ }^{48,49}$ has been developed as part of a growing integrative structural biological toolkit ${ }^{50}$ for pairing enhanced sampling MD simulations with experimental structural restraints.

Metainference ${ }^{49}$ is a quantitative and rigorous mathematical framework based on Bayesian inference. In this approach, a structural ensemble of the protein or peptide is generated by a multi-replica MD simulation guided by a hybrid energy function, which combines physicochemical information (the atomistic force field) with additional conformational restraints aimed at enforcing agreement of the structural ensemble of the peptide with the available experimental data. Furthermore, to accelerate sampling since structural states might be separated by huge energy barriers, metainference is combined with metadynamics (the Parallel-Bias (PBMetaD) flavor $)^{48}$. In this combined approach, an additional, timedependent bias potential is added to each replica and shared among all of them, in the spirit of the multiple-walkers ${ }^{51}$ approach. Metadynamic metainference addresses two of the major challenges in molecular simulations - (1) the limited accuracy of empirical force fields, which is improved by the introduction of experimental information, and (2) the time-scale limitations of standard MD, which is accelerated by the use of PBMetaD.

In this study, we make use of the N-terminal domain of statherin, SN15

(D $p$ SpSEEKFLRRIGRFG, where $\mathrm{pS}$ indicates a phosphorylated serine), which is often used as a model for statherin since it has nearly the same binding affinity for HAP as statherin ${ }^{26}$. Importantly, the binding of SN15 to HAP is greatly diminished if the serines are not phosphorylated. Remarkably, this binding affinity can be restored when the serine residues are replaced by aspartic acid ${ }^{31}$, leading to the model peptide $\mathrm{SNa} 15$

(DDDEEKFLRRIGRFG). We study the adsorption of SNa15 to different inorganic surfaces, namely HAP, silica $\left(\mathrm{SiO}_{2}\right)$, and titania $\left(\mathrm{TiO}_{2}\right)$. We explore the surface-bound structure of the peptide, identify the binding residues, and investigate the changes in binding upon changing the mineral substrate to which the peptide binds. For this, we use an integrative experimental and simulation approach, similar to recent studies, ${ }^{14,19,52}$, especially using NMR data as structural restraints in the molecular dynamics step to predict binding motifs of peptides on surfaces. ${ }^{48,53}$

To characterize binding experimentally, we use both adsorption isotherms and $1 \mathrm{D}^{13} \mathrm{C} \mathrm{CP}$ MAS, $1 \mathrm{D}^{15} \mathrm{~N} \mathrm{CP}$ MAS, and $2 \mathrm{D}{ }^{13} \mathrm{C}-{ }^{13} \mathrm{C}$ DARR experiments. These experiments provide chemical shifts for the backbone and side-chain which can resolve the peptide structure with high fidelity. Further, we use two modeling approaches - TALOS-N and molecular dynamics (MD) simulations. TALOS-N utilizes a protein database to predict the most likely structure of the peptide given the database and the experimentally-determined chemical shift data. ${ }^{45}$ However, since peptides often present an equilibrium ensemble of many structures with similar free-energies, even when bound to a surface, a single snapshot derived from TALOS-N might not provide a complete picture. ${ }^{49,54}$ Thus, we use MD simulations to 
generate an ensemble of surface-bound conformations consistent with experimental data. We use a recently proposed method named metadynamic metainference ${ }^{48,49}$ which uses

Bayesian inference to incorporate structural restraints derived from experimental data, while accounting for errors in both the experimental data and simulation models. This integrated approach allows us to resolve the peptide structure with higher fidelity than possible with a single structure prediction, allows us to zoom in on the specificity of the side-chains to the surface. Measured side-chain chemical shifts are not used in the molecular simulation step but kept aside for validation as illustrated in Schematic 1.

\section{RESULTS}

\section{Adsorption Isotherms}

To determine how $\mathrm{SNa} 15$ interacts with the $\mathrm{SiO}_{2}$ and $\mathrm{TiO}_{2}$ surfaces, Langmuir adsorption isotherm curves were measured (Figure 1). Isotherms for SNa15 interacting with HAP can be found in the literature. ${ }^{31}$ The curves were fit with Equation 1

$$
f=\mathrm{A} \frac{[\mathrm{SNa} 15]}{[\mathrm{SNa} 15]+\mathrm{K}_{\mathrm{d}}}
$$

where $\mathrm{K}_{\mathrm{d}}$ is the disassociation constant $(\mathrm{mM})$, $\mathrm{f}$ is the fractional saturation, $\mathrm{A}$ is a scaling factor (unitless), and [SNa15] is the concentration of free $\mathrm{SNa} 15$ in equilibrium (mM). The $\mathrm{K}_{\mathrm{d}}$ obtained from these data were $2.98 \mathrm{mM}$ and $2.30 \mathrm{mM}$ for $\mathrm{SNa} 15$ adsorbing onto $\mathrm{SiO}_{2}$ and $\mathrm{TiO}_{2}$, respectively. The maximum amounts of SNa15 adsorbed were $0.2 \mu \mathrm{mol} / \mathrm{m}^{2}$ and $1.2 \mu \mathrm{mol} / \mathrm{m}^{2}$ for $\mathrm{SiO}_{2}$ and $\mathrm{TiO}_{2}$, respectively.

\section{Chemical Shift Assignments}

Further, to obtain site-specific chemical shift assignments, $1 \mathrm{D}{ }^{15} \mathrm{~N}$ CP MAS and $1 \mathrm{D}{ }^{13} \mathrm{C} \mathrm{CP}$ MAS experiments were performed in conjunction with $2 \mathrm{D}{ }^{13} \mathrm{C}-{ }^{13} \mathrm{C}$ DARR experiments. We resolved and assigned most of the ${ }^{13} \mathrm{C}$ spins and the side-chain ${ }^{15} \mathrm{~N}$ spins in $\mathrm{SNa} 15$ containing up to two uniformly ${ }^{13} \mathrm{C}$ - and ${ }^{15} \mathrm{~N}$-enriched amino acids. To assign the chemical shifts for the entire peptide, seven isotopically enriched samples were analyzed, as shown in Table 1 . The only amino acids not assigned by this study are L8, I11, and the C-terminal G15.

An example of the data collected for each sample is shown in Figure 2. A $1 \mathrm{D}^{15} \mathrm{~N}$ CP MAS (Fig. 2a), 1D ${ }^{13} \mathrm{C} \mathrm{CP}$ MAS (Fig. 2b), and $2 \mathrm{D}^{13} \mathrm{C}-{ }^{13} \mathrm{C}$ DARR (Fig. 2c) spectrum was collected for each sample in order to make complete, unambiguous chemical shift assignments. Since the ${ }^{15} \mathrm{~N}$ amide spins had too much overlap, they could not be assigned unambiguously. Therefore, only the ${ }^{15} \mathrm{~N}$ side-chain spins were assigned.

Figure 3 illustrates how all chemical shift assignments are made for the entire neat SNa15 peptide. The cross-peak interactions are highlighted by the dashed red lines and labeled with the corresponding ${ }^{13} \mathrm{C}$ spins. These correlations allow for the assignment of unique chemical shifts. All ${ }^{13} \mathrm{C}$ chemical shift assignments were made via this method for the entire SNa15 peptide in the four phases studied: neat, adsorbed on $\mathrm{HAP}$, adsorbed on $\mathrm{SiO}_{2}$, and adsorbed 
on $\mathrm{TiO}_{2}$. Due to the broad nature of the ${ }^{13} \mathrm{C}$ lineshapes and the overlap in both carbonyl and aliphatic regions, as evident in Figure 2, 2D spectroscopy was deemed unnecessary to further resolve these assignments.

Additionally, changes in the chemical shifts $(\triangle \mathrm{CS}$ ) of the adsorbed peptide with reference to the peptide in water can provide information about (a) the structural changes of the peptide and (b) changes in local environment upon adsorption of the peptide to the surface. Figure 4 shows the chemical shifts of D2R9 in water and adsorbed to the three inorganic interfaces. The dashed lines emphasize positions of significant differences between these spectra. Notably, the resolution in the aliphatic region significantly decreases upon the adsorption of the peptide, necessitating the use of 2D spectroscopy.

$\Delta \mathrm{CS}$ values for the backbone of SNa15 at different surfaces are plotted in Figure 5. These values are obtained by subtracting the chemical shift of the ${ }^{13} \mathrm{C}$ spin in neat $\mathrm{SNa} 15$ from the corresponding ${ }^{13} \mathrm{C}$ spin in the adsorbed $\mathrm{SNa} 15$ peptide. A positive $\Delta \mathrm{CS}$ indicates a downfield perturbation of the chemical shift (higher ppm, less shielded), while a negative $\Delta \mathrm{CS}$ indicates an upfield perturbation of the chemical shift (lower ppm, more shielded).

From Figure 5, it is evident that some chemical shift trends are common for all three mineral systems. For the case of the $\Delta \mathrm{CS}$ for ${ }^{13} \mathrm{CO}, \mathrm{E} 4$ exhibits upfield shifts and $\mathrm{G} 12$ exhibits downfield shifts. Similarly, all three adsorbed phases experience large downfield shifts for the ${ }^{13} \mathrm{Ca}$ spins of G12 and D2. Additionally, they all experience a pronounced downfield shift for the ${ }^{13} \mathrm{C} \beta$ spins of D2 and D3 while there is a pronounced upfield shift for the ${ }^{13} \mathrm{Ca}$ spins of R13 and the ${ }^{13} \mathrm{C} \beta$ spins of R10. The fact that $\Delta \mathrm{CS}$ of these residues have the same trend at all interfaces indicates that these regions in the peptide display similar structural changes when adsorbed to any of these surfaces. Specifically, the N-terminus (D2-E4) and the C-terminus (R10, G12, and R13) experience similar conformational changes upon adsorption to $\mathrm{HAP}, \mathrm{SiO}_{2}$, and $\mathrm{TiO}_{2}$. Additionally, there are pronounced backbone $\Delta \mathrm{CS}$ changes for $\mathrm{SNa} 15$ that are unique to each mineral phase and might be useful in highlighting the unique conformation of SNa15 adsorbed to each mineral phase, which we further explore with MD simulations.

$\Delta \mathrm{CS}$ values for the side-chains of SNa15 at different surfaces are plotted in Figure 6. SNa15 experiences downfield shifts for the ${ }^{13} \mathrm{C} \gamma$ of D2 and D3 and the ${ }^{13} \mathrm{C} \delta$ of $\mathrm{E} 4$ and E5 across all mineral surfaces. These spins correspond to the side-chain carboxyl groups in the aspartic acid and glutamic acid residues in the $\mathrm{N}$-terminus of SNa15, respectively. The ${ }^{13} \mathrm{CO}$ shifts of E4 and E5 are also accompanied by large downfield shifts of the ${ }^{13} \mathrm{C} \gamma$ spins for SNa15 upon adsorption to all three mineral surfaces. The basic residues of SNa15 (K6, R9, R10, and R13) generally experience less pronounced and less consistent perturbations across the three surfaces. There is a consistent upfield shift for both the ${ }^{13} \mathrm{C} \gamma$ and ${ }^{13} \mathrm{C} \delta$ spins of R13 in $\mathrm{SNa} 15$. Additionally, there is an upfield shift of the ${ }^{13} \mathrm{C} \varepsilon$ spin of K6 upon adsorption to HAP and $\mathrm{TiO}_{2}$, although not $\mathrm{SiO}_{2}$. Typically, upfield shifts of lysine ${ }^{13} \mathrm{C} \varepsilon$ spins indicate proximity to a negatively-charged mineral surface. ${ }^{55}$

Figure 7 shows the ${ }^{15} \mathrm{~N}$ side-chain $\Delta \mathrm{CS}$ values for different surfaces. Downfield perturbations are observed for $\mathrm{R} 9{ }^{15} \mathrm{~N}$ shifts upon adsorption to $\mathrm{HAP}$ (2.3 ppm), $\mathrm{SiO}_{2}$ (1.3 
ppm), and $\mathrm{TiO}_{2}(3.5 \mathrm{ppm})$, indicating interactions with the phosphate buffer and/or the surfaces. The $\mathrm{K} 6{ }^{15} \mathrm{~N} \zeta$ spin also experiences a downfield perturbation, albeit less pronounced, upon adsorption to $\mathrm{HAP}(0.9 \mathrm{ppm}), \mathrm{SiO}_{2}(0.2 \mathrm{ppm})$, and $\mathrm{TiO}_{2}(0.2 \mathrm{ppm})$.

\section{SNa15 Secondary Structure Predictions from TALOS-N}

Following the conventional practice for structure prediction from ssNMR data, the backbone ${ }^{13} \mathrm{C}$ chemical shifts for SNa15 were input to the TALOS-N ${ }^{52}$ program, that predicts the $\phi / \psi$ torsion angles (Supplementary Information). Chimera ${ }^{56}$ was used to visualize the structure that corresponds to these predicted torsional angles (Figure 8 and Figure 9). Figure 8 shows that $\mathrm{SNa} 15$ has some a-helical structure in each surface-bound state and that SNa15 is largely unstructured when adsorbed to $\mathrm{SiO}_{2}$. For neat $\mathrm{SNa} 15$, the $\phi / \psi$ torsion angles for E4I1 1 are clustered around the accepted $a$-helical values (-57/-47), while the $\phi / \psi$ torsion angles for R13 and F14 are clustered around (-80/+150), indicating a loss of helicity at the C-terminus and a more extended secondary structure. Largely, the torsion angles upon adsorption to HAP are similar to those in the hydrated solid state, as evident by the similarity in structures of A and C (Figure 8). In the case of HAP, residues E5-I11 exhibit ahelical character, while residues in the N-terminus (D2-E4), and C-terminus (R13-F14) exhibit more extended structures. In contrast, upon adsorption on $\mathrm{TiO}_{2}$, the a-helix is extended farther into the $\mathrm{N}$-terminus; the $\phi / \psi$ angles for D2-I11 are all clustered around $a-$ helical values, although the C-terminus remains extended, as seen in HAP. Remarkably, the structure of $\mathrm{SNa} 15$ differs greatly upon adsorption to $\mathrm{SiO}_{2}$, when compared to the other systems. The helical region of $\mathrm{SNa} 15-\mathrm{SiO}_{2}$ is limited to K6-R9.

The end-view of each predicted structures is visualized in Figure 9 to highlight helical content and the relative orientation of the side-chains. In the mineral systems, F7 and F14 are pointing in different directions. This is consistent with chemical shift data, relaxation dynamics $\left(\mathrm{T}_{1} / \mathrm{T}_{1 \rho}\right)^{20,27},{ }^{13} \mathrm{C}\left\{{ }^{31} \mathrm{P}\right\}$ REDOR ${ }^{20},{ }^{2} \mathrm{H}$ ssNMR ${ }^{27}$, and NEXAFS ${ }^{24}$ data, which all conclude that F7 is far from the HAP surface (at least $7 \AA$ ) while F14 is close to (within $4 \AA$ ) and interacting with the surface. The $\Delta \mathrm{CS}$ values in this study support this theory, since there are significant perturbations for $\mathrm{F} 14\left({ }^{13} \mathrm{C} \gamma,{ }^{13} \mathrm{C} \delta,{ }^{13} \mathrm{C} \varepsilon\right.$, and ${ }^{13} \mathrm{C} \zeta$ data), yet much smaller perturbations for the same shifts of F7. Further, it has been posited that F14 is in a nearparallel orientation to HAP, thus exposing the delocalized electrons in the phenyl ring. ${ }^{57}$

\section{SNa15 Secondary Structure Predictions of Adsorbed Peptides from MD Simulations}

Further, MD is used to generate an ensemble of conformations of the peptide consistent with the experimentally measured chemical shifts. The backbone ${ }^{13} \mathrm{CO},{ }^{13} \mathrm{Ca}$, and ${ }^{13} \mathrm{C} \beta$ chemical shift data for $\mathrm{SNa} 15-\mathrm{HAP}, \mathrm{SNa} 15-\mathrm{SiO}_{2}$, and $\mathrm{SNa} 15-\mathrm{TiO}_{2}$ were used to restrain an ensemble of configurations using the metadynamic metainference approach ${ }^{48}$ (See Methods). The restraints are applied to the average chemical shifts across many simulation replicas, thereby limiting the average deviation of the backbone chemical shift to be within the error predicted by experiments. The calculated side-chain chemical shifts are not directly used in the simulations or analysis of the clusters and provide a posteriori validation of our approach. Root mean squared errors (RMSE) of the backbone (training error) and side chain (validation error) for the surface adsorbed peptides are provided in Table 2. We see that the error in both the backbone and side chain chemical shifts are between $1.48-2.25 \mathrm{ppm}$, 
which denotes agreement with experimental data (experimental error $\sim 2 \mathrm{ppm}$ ), providing strong evidence that the ensemble of peptide conformations generated by the metadynamic metainference simulation are consistent with the experimental data.

We next determined the most likely conformations of the peptide generated by the MD simulation by performing a clustering (See Methods). The center of the top three most likely clusters of peptide backbone conformations (and their weights determined from postprocessing of the metadynamics simulations) along with the representative structure from TALOS-N are shown in Figure 10. For the case of $\mathrm{SiO}_{2}$, all conformations are random coils with a helical middle section. Noticeably, the structure predicted by TALOS-N has the same structural motif. The MD-predicted structures of SNa15 on HAP show similar amounts of secondary structure, with more variance in the number of helical turns in the center. For both $\mathrm{TiO}_{2}$ and HAP surfaces, the TALOS-N predicted structure displays a greater level of helicity (with unstructured ends) than the MD-predicted structure. However, the top three peptide structures encompass the helical components present in the TALOS-N structures. This demonstrates the need to view the structure of SNa15 on mineral oxide surfaces as an 'ensemble' and not a single entity. We note that in all cases, the exact structure predicted by TALOS-N can be found within the biased MD simulations, although it does not appear in the top three reweighted cluster centers shown here.

Further, to ascertain which residues are interacting with the surface, the top three clusters were placed near the respective surface and simulated for $50 \mathrm{~ns}$ (with the backbone restrained using an RMSD restraint on the Ca atoms) (see Figure S4-7). For the case of the HAP surface (Figure S4), SNa15 is anchored to the interface by a mixture of basic (R9, K6, and R10) and acidic (D1, D2, and E5) residues. Since the surface is neutral overall, and has local pockets of positive and negative charge, it is understandable that the peptide needs both types of binding residues to bind to the surface. $\mathrm{The}^{\mathrm{TiO}} 2$ surface is a negatively charged surface. Consequently, basic residues (R10, and K6) allow SNa15 to bind to the the surface (Figure S5). Acidic residues (D1, D2, and D3) interact with mobile sodium ions. Similar to the $\mathrm{TiO}_{2}$ surface, the $\mathrm{SiO}_{2}$ surface is also negatively charged and neutralized with mobile, displaceable sodium ions. Therefore, SNa15 is also anchored with basic residues only (R13 and R9) (Figure S6). Notably, neutral, hydrophobic residues like F14, F7, and I11 also approach the surface. On approach, F14 and F7 lay flat on the surface.

Additionally, the contact profile of individual residues with the surface is explored. Several residues show a bimodal distribution of contacts on the $\mathrm{SiO}_{2}$ the surface (D2, D3, K6, F7, R9, and F14) (Figure S7). Further, most N-terminus residues of SNa15 are closer to the surface on $\mathrm{SiO}_{2}$ and $\mathrm{TiO}_{2}$ than they are on the HAP surface (Figure S7). Notably, all SNa15 residues are in closer contact with the $\mathrm{SiO}_{2}$ surface than the other surfaces. We hypothesize that greater contact with the surface might promote the SNa15 residues to unfold more, thus $\mathrm{SNa} 15$ has much lesser helical content on the $\mathrm{SiO}_{2}$ surface.

Finally, the distribution of secondary structure elements along the peptide is determined (Figure S8). The results indicate helical structures in the middle residues of SNa15 peptide on all three mineral surfaces. However, the peptide is more likely to be helical on the $\mathrm{TiO}_{2}$ surface, as also seen in the TALOS-N predictions. SNa15 has significant random coil 
structure on the HAP surface. Finally, $\mathrm{SNa} 15$ shows distinct bends on the $\mathrm{SiO}_{2}$ surface, which is also evident in the TALOS-N prediction.

\section{DISCUSSION}

Both the structure of the protein and the interaction of its side-chains with the surface are integral to the process of recognition of biomineral surfaces by proteins. Expectedly, the foundational goals in this field are centered around the determination of protein secondary structure, the evaluation of changes in structure upon adsorption, and the estimation of the proximity or orientation of amino acids to the surface. To further these goals, we have chosen the model peptide SNa15 and elucidated its structure upon binding to three naturally occurring mineral surfaces $\left(\mathrm{HAP}, \mathrm{SiO}_{2}\right.$, and $\left.\mathrm{TiO}_{2}\right)$. In fact, we have demonstrated an integrated approach that pairs experimental data with $\mathrm{MD}$ simulations to make more robust predictions about the ensemble of surface adsorbed structures. Experimentally, we used 1D and 2D ssNMR techniques to determine the secondary structure of SNa15 in the pure, i.e. unadsorbed solid state, and when adsorbed to $\mathrm{HAP}, \mathrm{SiO}_{2}$, and $\mathrm{TiO}_{2}$ surfaces. On the modeling front, we used the structure prediction software TALOS-N, and classical all-atom MD simulations (with metadynamic metainference enhanced sampling) to generate an ensemble of conformations of the peptide on the surface, which are consistent with the experimental data.

Overall, the backbone $\left({ }^{13} \mathrm{CO},{ }^{13} \mathrm{Ca}\right.$, and $\left.{ }^{13} \mathrm{C} \beta\right)$ chemical shift data and subsequent TALOS$\mathrm{N}^{52}$ predictions indicate that $\mathrm{SNa} 15$ is helical (with unraveling at the termini) in water, and when adsorbed to $\mathrm{HAP}$ and $\mathrm{TiO}_{2}$. In contrast, the peptide is predicted to be largely unfolded on the $\mathrm{SiO}_{2}$ surface. The picture, when viewed from the perspective of integrated MD +ssNMR is more nuanced, with a need to explore in more detail the full conformational ensemble.

Further, we explore the interaction of various amino-acid side-chains with the surface via the $\Delta \mathrm{CS}$ for the side-chain ${ }^{13} \mathrm{C}$ spins. Notably, large downfield perturbations in the $\Delta \mathrm{CS}$ of $\mathrm{E} 4$, E5, and F14 (in all cases) suggest that they are interacting with each surface. There are large downfield perturbations for the side-chain ${ }^{13} \mathrm{C} \gamma$ and ${ }^{13} \mathrm{C} \delta$ spins of E4 and E5 (Fig. 6a-b). In fact, this CS perturbation is attributed to the decreased shielding of the carboxyl group due to its interaction with the surface. ${ }^{55}$ Fernandez et al. ${ }^{55}$ also noted similar downfield shifts in ${ }^{13} \mathrm{C} \delta$ spins ( $2 \mathrm{ppm}$ ) in their study of poly-L-glutamic acid adsorbed on $\mathrm{HAP}$ and $\mathrm{SiO}_{2}$. In our study, these downfield shifts range from $3-5.3 \mathrm{ppm}$ indicating a stronger effect than that seen by Fernandez et al. ${ }^{55}$ Moreover, since the perturbations are roughly the same magnitude within error for both residues, this suggests a similar degree of contact with the surface. This contrasts with the predicted behavior of SN15 and statherin on HAP, where only E5 was proposed to interact with HAP. ${ }^{23}$ In fact, MD simulations predict that E4 and E5 have a much higher degree of conformational flexibility (Figure S7) on HAP compared to $\mathrm{SiO} 2$ and TiO2. Notably, NMR-derived side-chain constraints were not included in the MD simulation, therefore some deviations in the side-chain behavior is expected.

Amongst the aromatic groups, we observe that F14 is also interacting significantly with the surface. The role of phenylalanine residues in the binding of statherin to HAP has been 
studied extensively. ${ }^{20,24,27}$ Gibson and coworkers ${ }^{20}$ studied the role of F7 and F14 in SN15 adsorption to HAP through isotropic chemical shift perturbations, ${ }^{13} \mathrm{C}\left\{{ }^{31} \mathrm{P}\right\} \mathrm{REDOR}$, and $\mathrm{T}_{1 \rho}$ relaxation measurements. They found that when compared to F7, F14 is closer to the surface and is more dynamically constrained. In fact, F7 is observed to be oriented away from the HAP surface. ${ }^{20}$ The study by Weidner and coworkers ${ }^{24}$ used NEXAFS and SFG also corroborates this observation. Correspondingly, in this study, we note large $\Delta \mathrm{CS}$ for F14 and minimal $\Delta \mathrm{CS}$ for F7 (Fig. 5-6). MD simulations also predict the interaction of F14 with $\mathrm{SiO}_{2}$. In fact, the ${ }^{13} \mathrm{CO}$ and ${ }^{13} \mathrm{Ca}$ chemical shift data also show that $\mathrm{F} 14$ behaves differently in HAP than the other two surfaces.

In the case of basic residues, there are negligible perturbations for most of the side-chain ${ }^{13} \mathrm{C}$ spins for K6, R9, and R10. MD simulations also show that other basics residues (K6, R9, and R10) are away from the surface (Figure S7). This suggests that these residues do not specifically adsorb to or identify any of these surfaces. In fact, previous studies where the 4 basic residues (K6, R9, R10, R13) of statherin were mutated to alanine have shown that individually, none of these residues are crucial to binding. ${ }^{29}$ However, as a group they act to decrease the overall charge of statherin, thus reducing repulsive protein-protein interactions and promoting a higher surface affinity and coverage. ${ }^{29}$

In contrast, the $\mathrm{R} 13{ }^{13} \mathrm{C} \gamma$ and ${ }^{13} \mathrm{C} \delta$ spins experience significant perturbations in the range of -0.9 to $-2 \mathrm{ppm}$. This suggests that R13 interacts with the surfaces while the remaining basic residues do not. From the end-view of TALOS-N predicted structures (Figure 9), it is evident that the R13 side-chain is oriented on the same face of SNa15 as E4, E5, and F14 (the residues that are hypothesized to interact with the surfaces). The behavior of R13 is corroborated with MD simulations only in the case $\mathrm{SiO}_{2}$.

Finally, we observe that D2 and D3 are also crucial to the recognition of surfaces. In the case of HAP, D2 and D3 are oriented along the hypothesized binding face of SNa15. These residues experience a downfield shift of 1.2 and $1.3 \mathrm{ppm}$, respectively, upon adsorption. This is also true for adsorption on $\mathrm{SiO}_{2}$, since $\mathrm{D} 2$ and $\mathrm{D} 3$ both experience a downfield shift of 2 ppm. However, in the case of $\mathrm{TiO}_{2}$, only D2 is oriented along the binding face (predicted by a significant $\triangle \mathrm{CS}$ in $\mathrm{D} 2$ only). From MD simulations, we see that $\mathrm{D} 2$ contribute to the binding of $\mathrm{SNa} 15$ to all surfaces (Figure S7) while D3 contributes to the binding to $\mathrm{SiO}_{2}$ and $\mathrm{TiO}_{2}$.

Based on the information above, we hypothesize that the binding domain of SNa15 consists of some residues from N-terminus (D2-E5) and C-terminus (R13 and F14) residues for binding to $\mathrm{HAP}$ and $\mathrm{SiO}_{2}$. For the case of $\mathrm{TiO}_{2}$, D3-E5, R13, and F14 residues contribute to binding. MD simulations predict that $\mathrm{SNa} 15$ binds from the N-terminus on the HAP and $\mathrm{TiO}_{2}$ surfaces, and from the $\mathrm{C}$-terminus on the $\mathrm{SiO}_{2}$. The residues composing the hypothesized binding domain are all oriented on the same face of SNa15 and all experience significant chemical shift perturbations upon adsorption. In fact, the lack of a-helical character in the $\mathrm{N}$-terminus allows consecutive acidic residues to be positioned along the same face and interact completely with the surface. 
Since SNa15 is comparable to other model peptides (SN15) and its parent protein statherin, it is possible to compare the behavior of $\mathrm{SNa} 15$ with previously reported observation about the other peptides. In fact, prior studies of statherin and SN15 on HAP were based on distance measurements obtained from dipolar couplings between ${ }^{13} \mathrm{C}$ and ${ }^{15} \mathrm{~N}$ spins within the peptides and between ${ }^{13} \mathrm{C}$ spins in peptide side chains and ${ }^{31} \mathrm{P}$ spins in the HAP surface. Since these studies and the current studies results in predictions of the peptide structure, it is useful to compare these results, albeit qualitatively. For example, the distorted helical structure obtained for SNa15 on HAP, obtained by analysis of the ${ }^{13} \mathrm{CO},{ }^{13} \mathrm{Ca}$, and ${ }^{13} \mathrm{C} \beta$ chemical shifts via TALOS and MD simulations, is in agreement with earlier dipolar coupling-based studies of the structure of SN15 and statherin on HAP. ${ }^{15,31,37}$ Our present study of SNa15 and prior studies of statherin and SN15 find that the acidic N-termini of SNa15 and SN15 interact strongly with the HAP surface, but details of exactly which side chains are involved in surface interactions differ. Downfield changes to the chemical shifts of the $\gamma$ and $\delta$ carboxyl ${ }^{13} \mathrm{C}$ spins in $\mathrm{SNa} 15$ 's $\mathrm{D}_{2} \mathrm{D}_{3} \mathrm{E}_{4} \mathrm{E}_{5}$ moiety observed upon adsorption to HAP indicate interactions with the HAP surface. Relaxation and chemical shift line shape studies of $\mathrm{pS} 2$ and $\mathrm{pS} 3$ in SN15 on HAP similarly find that these N-terminal amino acids are anchored to the surface ${ }^{36}$, but a ${ }^{13} \mathrm{C}\left\{{ }^{31} \mathrm{P}\right\}$ REDOR study finds that the ${ }^{13} \mathrm{C} \delta$ spin of E5 is much closer to the HAP surface than the carboxyl group of $\mathrm{E} 4 .{ }^{19}$ Based on ${ }^{13} \mathrm{C} \zeta$ upfield chemical shift changes upon adsorption to HAP, only R13 is assumed to interact with the HAP surface in SNa15, while a ${ }^{13} \mathrm{C}\left\{{ }^{31} \mathrm{P}\right\}$ REDOR study of statherin on HAP finds that the ${ }^{13} \mathrm{C} \varepsilon$ spin of $\mathrm{K} 6$ and ${ }^{13} \mathrm{C} \zeta$ spins of R9 and R10 are close to the HAP surface. Some of these differences may result from variations in local secondary structure, where for example the substitution of $\mathrm{D}$ for $\mathrm{pS}$ at positions 2 and 3 in SNa15 may perturb the local helical structure making it possible to simultaneously expose E4 and E5 in SNa15 to the surface. The apparent differences between exposure of basic amino acids in SN15 and SNa15 to the HAP surface may similarly result from structural changes in the acidic portion of the Nterminus that perturb the surface orientation of the basic amino acids.

Another factor to consider is the effect that the orientation of the side chain has on $\Delta \mathrm{CS}$ values. In a study of SK rich peptides in $\mathrm{SiO}_{2}$ and $\mathrm{TiO}_{2}$ composites, density functional theory (DFT) calculations showed that the chemical shift of ${ }^{13} \mathrm{C} \varepsilon$ spins in lysine side chains has a large upfield $\Delta \mathrm{CS}$ when the side chain is oriented perpendicular to the surface, but the $\Delta \mathrm{CS}$ is greatly diminished for ${ }^{13} \mathrm{C} \varepsilon$ when the side chain is oriented parallel to the surface. ${ }^{58}$ Also, for lysine ${ }^{13} \mathrm{C} \varepsilon$ spins $\Delta \mathrm{CS}$ values drop off rapidly as a function of the distance between the amine group and the surface. For example, when the distance from the lysine side chain amine to the $\mathrm{SiO}_{2}$ surface exceeds 3 Angstroms $\Delta \mathrm{CS}$ perturbations are comparable to experimental error.

Some of the results obtained in our study of SNa15-mineral interactions are similar to results reported in other studies of statherin-mineral interactions. For example structural dispersion of SN15 on HAP was observed in a solid state NMR study by Chan et al ${ }^{81}$ Those workers observed two sets of cross peaks for K6 in the $1 \mathrm{D}^{13} \mathrm{C}-{ }^{13} \mathrm{C}$ correlated spectrum.. The ${ }^{13} \mathrm{Ca}$ chemical shift of the major component $(66 \%)$ was close to that observed for free (i.e. helically structured) SN15 while the minor component chemical shift was close to random coil. A study of differential adsorption of statherin and the statherin peptide SN21 on HAP and silica by ellipsometry ${ }^{82}$ showed higher adsorption levels for both peptides on HAP 
versus hydrophilic silica. This observation was attributed by the authors in part to repulsion between the negatively changed surface and the negatively charged side chains at the Nterminus.

However, a significant result of our study is that differential adsorption of Sna15 on $\mathrm{TiO}_{2}$ and $\mathrm{HAP}$ versus $\mathrm{SiO}_{2}$, is accompanied by differential structuring on these surfaces, i.e. more helical structuring on $\mathrm{TiO}_{2}$ and $\mathrm{HAP}$ versus $\mathrm{SiO}_{2}$.. If this differential structuring effect can be demonstrated for other proteins on mineral surfaces, then the detailed surface structure of the protein and the arraying of side chains is an important component of its surface interactions and may, for example, explain in part the affinity of tissue cells for particular implant coatings It has long been known that interactions between tissue-generating cells and implant surfaces are mediated by a proteinaceous layer. ${ }^{83-85}$ Ideally a layer of specifically adsorbed proteins promotes cell adhesion to the implant surface and normal cellular response, leading ultimately to integration of the implant with the surrounding tissue. Non-specific adsorption of proteins or the presence of proteins in an unstructured or otherwise unrecognized state may result in a foreign body response and implant failure. It has been observed that osteoblasts differentiation is enhanced on $\mathrm{TiO} 2$ coatings versus $\mathrm{SiO} 2$ coating. ${ }^{86}$ Although further studies protein surface structures are required to support a general explanation, the ability of $\mathrm{TiO}_{2}$ to support a layer of structured adhesion proteins may contribute to its ability to support osteoblast differentiation.

\section{CONCLUSION}

This study of the adsorption of $\mathrm{SNa} 15$ onto $\mathrm{HAP}, \mathrm{SiO}_{2}$, and $\mathrm{TiO}_{2}$ surfaces demonstrates an integrated approach that pairs ssNMR with advanced MD simulations as a means to predict ensembles of surface-bound peptide structures. Measured adsorption isotherms and companion structure predictions from the software TALOS-N provide additional characterization of the systems. In contrast to using TALOS-N to predict a single set of dihedral angles, the integrated approach allows for structure prediction of an entire conformational ensemble with average backbone chemical shifts constrained to the measured experimental values. This approach is thus a promising way to estimate not only the conformational ensemble, but also the key binding residues to the surface and orientation of the adsorbed biomolecule.

Although this method can be applied to many peptide/surface systems in the future to study biomineralization processes, the approach has potential areas for future investigation. First, there is a continued need to improve surface potentials and representation of accurate surface chemistries for use in MD simulations of peptide adsorption, even with metadynamic metainference approach to help overcome systematic errors. Second, DFT can be used to provide accurate estimates of the surface response of amino acids such as those shown here and to help provide an assessment of the accuracy of using the SHIFTX and CAMSHIFT methods for peptides on surfaces. 


\section{METHODS}

\section{Peptide Synthesis}

All natural and uniformly labeled ${ }^{13} \mathrm{C}$ and ${ }^{15} \mathrm{~N}$ amino acids were purchased from Sigma Aldrich (St. Louis, MO). Preloaded Fmoc-protected Wang resin was purchased from EMD Millipore (Billerica, MA). All other reagents were purchased from Sigma Aldrich (St. Louis, MO) and used without purification. Peptides were synthesized on a CEM Liberty Blue peptide synthesizer using a standard 9-fluorenylmethoxycarbonyl (FMOC) and tert-butyl protection scheme. Preloaded Fmoc-protected Wang resin was used for solid phase synthesis. Peptides were cleaved from the resin in a $10 \mathrm{~mL}$ solution of 95:2.5:2.5 trifluoroacetic acid: triisopropylsilane (TRIS): water mixture per 1.0 gram of peptide/resin. The resulting filtrate was added dropwise into cold tert-butyl methyl ether, followed by centrifugation and three rinses of the resulting solids with $40 \mathrm{~mL}$ of cold tert-butyl methyl ether. Peptides were purified using RP-HPLC (Varian ProStar HPLC, Alltima WP C4 column, $5 \mathrm{~mL} / \mathrm{min}$, eluent A: water with $0.2 \%$ TFA, eluent B: acetonitrile with $0.2 \%$ TFA), using a gradient of $15-50 \%$ B over 40 minutes. Chromatograms were generated by observing the UV absorbance at $254 \mathrm{~nm}$, and the analyte was verified by mass spectrometry. The fractions were then lyophilized, resulting in the pure peptide.

\section{Surface Area Determination}

HAP (product number 677418; a synthetic, crystalline nanopowder with a reported particle size <200 nm), $\mathrm{SiO}_{2}$ (product number 637246; a spherical, porous nanopowder with a reported particle size of 5-20 nm), and $\mathrm{TiO}_{2}$ (product number 637262; a rutile titanium (IV) oxide nanopowder with a reported particle size $<100 \mathrm{~nm}$ ) nanoparticles were purchased from Sigma Aldrich (St. Louis, MO) and used without purification. The surface area of the HAP, $\mathrm{SiO}_{2}$, and $\mathrm{TiO}_{2}$ nanoparticles was determined using a Nova 4200e Surface Area and Pore Size Analyzer from Quantachrome Instruments. BET measurements showed a surface area of $34.4 \mathrm{~m}^{2} / \mathrm{g}$ for $\mathrm{HAP}, 331.9 \mathrm{~m}^{2} / \mathrm{g}$ for $\mathrm{SiO}_{2}$, and $28.6 \mathrm{~m}^{2} / \mathrm{g}$ for $\mathrm{TiO}_{2}$ nanoparticles.

\section{Adsorption Isotherms}

Known concentrations of SNa15 (1ml) were equilibrated with $10 \mathrm{mg}$ of $\mathrm{HAP}, \mathrm{SiO}_{2}$, or $\mathrm{TiO}_{2}$ nanoparticles for 4 hours in phosphate buffer $(100 \mathrm{mM}, \mathrm{pH}=7.4)$. After adsorption, the solid nanoparticles were separated from the mixture via centrifugation at $13000 \mathrm{x} g$ for 15 minutes. The peptide concentrations in the supernatant solutions were measured using an Agilent 8453 Diode Array UV-Vis Spectrophotometer and compared with the initial concentrations.

\section{ssNMR Sample Preparation}

SNa15 (2mM, 5ml) was equilibrated with $60 \mathrm{mg}$ of mineral nanoparticle for 4 hours in phosphate buffer $(100 \mathrm{mM}, \mathrm{pH}=7.4)$. After adsorption, the solid was separated from the mixture via centrifugation at $13000 \mathrm{x}$ g for 15 minutes. The supernatant was discarded, and the remaining solid was dried in vacuo. 
All solid-state NMR experiments were conducted using a 16.4 T magnetic field (proton resonant field of $700.18 \mathrm{MHz}$ ) on a Bruker Avance III spectrometer fitted with a ${ }^{1} \mathrm{H}\left\{{ }^{13} \mathrm{C}\right.$, $\left.{ }^{15} \mathrm{~N}\right\} 3.2 \mathrm{~mm}$ MAS probe. The spinning speed for all experiments is $15 \mathrm{kHz} \pm 5 \mathrm{~Hz}$, and is regulated by a Bruker MAS controller unit. All experiments were run at room temperature. $1 \mathrm{D}^{13} \mathrm{C}$ CP MAS experiments were collected using a $4 \mu$ s proton $\pi / 2$ pulse, a contact time of $1.2 \mathrm{~ms}$, and a recycle delay of $2 \mathrm{~s}$. Neat samples required $2 \mathrm{k}$ scans while adsorbed samples required $8 \mathrm{k}$ scans. $1 \mathrm{D}^{15} \mathrm{~N}$ CP MAS experiments were collected using a $4 \mu$ s proton $\pi / 2$ pulse, a contact time of $2 \mathrm{~ms}$, and a recycle delay of $2 \mathrm{~s}$. Neat samples required $4 \mathrm{k}$ scans while adsorbed samples required $32 \mathrm{k}$ scans. All ${ }^{13} \mathrm{C}$ chemical shifts reported were indirectly referenced to tetramethylsilane (TMS) in the solid-state using adamantane ( $\delta=38.48 \mathrm{ppm}) .{ }^{59}$ All ${ }^{15} \mathrm{~N}$ chemical shifts reported were indirectly referenced to $\mathrm{NH}_{3}{ }^{+}$in the solid-state using glycine $(\delta=33.4 \mathrm{ppm}) .{ }^{60} 2 \mathrm{D}{ }^{13} \mathrm{C}-{ }^{13} \mathrm{C}$ DARR experiments were collected with a $1.2 \mathrm{~ms}$ contact time, a $4 \mu$ s proton $\pi / 2$ pulse, and a $4 \mu \mathrm{s}{ }^{13} \mathrm{C} \pi / 2$ pulse. Mixing times were $60 \mathrm{~ms}$. For neat samples, there were 256 points in the indirectly detected dimension (F1) and $1 \mathrm{k}$ points in the directly detected dimension (F2). For adsorbed samples, there were 128 points in F1 and $1 \mathrm{k}$ points in $\mathrm{F} 2$. Again, the chemical shifts reported were indirectly referenced to TMS in the solid-state using adamantane $(\delta=38.48 \mathrm{ppm}) .{ }^{59}$

\section{Molecular Dynamics Simulations}

System Setup-The structure of $\mathrm{SNa} 15$ peptide when adsorbed onto $\mathrm{HAP}, \mathrm{SiO}_{2}$, and $\mathrm{TiO}_{2}$ surfaces was probed using classical all-atom molecular dynamics simulations. The peptide was modeled using the AMBER99SB-ILDN force field. ${ }^{61}$ Water was modeled using SPC/E water model. ${ }^{62} \mathrm{HAP}$ and $\mathrm{SiO}_{2}$ were modeled using the INTERFACE force field, ${ }^{63}$ while the $\mathrm{TiO}_{2}$ was modeled using the force field by Predota et al. ${ }^{64}$ (details about surface construction in SI). These models were chosen according to previously published studies of peptide and surfaces. ${ }^{65-69}$ The HAP surfacs was neutral, whereas the negatively-charged $\mathrm{TiO}_{2}$ and $\mathrm{SiO}_{2}$ surfaces was neutralized by 72 and $80 \mathrm{Na}^{+}$ions, respectively. The peptide had a net negative charge of -1 which was neutralized by a single $\mathrm{Na}^{+}$ion.

For each peptide-surface system, a slab of the inorganic surface was created, and the peptide was placed near the surface. This system was then solvated with water (7935 waters for HAP, 8273 water for $\mathrm{SiO}_{2}$, and 8134 waters for $\mathrm{TiO}_{2}$ ). Unfavorable contacts during this packing were removed by using a steepest descent algorithm that minimized the energy of the system. The pressure of the system was equilibrated to 1 bar by propagating the system in the NPT ensemble (Temperature $=300 \mathrm{~K}$; Pressure $=1 \mathrm{bar}$ ) for $1 \mathrm{~ns}$. The semi-isotropic version of Berendsen barostat ${ }^{70}$ ( $\mathrm{tau}=1.0 \mathrm{ps}$ ) was used so that only the z-axis of the box changed to correct the pressure of the system. The Bussi-Donadio-Parrinello thermostat ${ }^{71}$ $(\operatorname{tau}=0.1 \mathrm{ps})$ was used to maintain the temperature at $300 \mathrm{~K}$. For the production run, the system was propagated in the NVT ensemble $(300 \mathrm{~K}$ ) for a total of 2 microseconds with 4 replicas (500ns/replica). For all simulations, long-range electrostatics were treated with particle-mesh Ewald summation. ${ }^{72}$ A cut-off of $1.0 \mathrm{~nm}$ was used for Lennard-jones and coulombic interactions. All bonds between hydrogens and heavy atoms were constrained using the LINCS algorithm ${ }^{73}$ allowing for a simulation time step of $2 \mathrm{fs}$. All simulations were conducted using GROMACS 2016. ${ }^{74}$ 
Biasing Scheme-We used the parallel bias metadynamics ${ }^{75}$ scheme which allows for efficient sampling of such high-dimensional free energy landscapes. To ensure that all binding conformations of the peptide were explored, we biased 4 collective variable -3 for structural elements of the peptide (radius of gyration, alpha-helical and $3_{10}$-helix coordination numbers) and 1 for the distance of the peptide from the surface. The radius of gyration was calculated using all alpha carbon atoms. Coordination numbers were calculated using carbonyl oxygen and amide hydrogen contacts within $0.30 \mathrm{~nm}$ of the $\mathrm{i}^{\text {th }}$ and $\mathrm{i}+4^{\text {th }}$ residues for the alpha-helix and $i^{\text {th }}$ and $i+3^{\text {th }}$ residues for the $310^{\text {-helix. The distance was }}$ calculated by using the z-distance between the center of mass of all alpha-carbon atoms and a reference surface atom. The peptide was restrained to explore only distances below $2 \mathrm{~nm}$ so that the peptide only explores surface-bound structures. The parameters for the bias were - initial hill height of $1.2552 \mathrm{~kJ} / \mathrm{mol}$, hill deposition pace of 1 hill/500 steps, biasfactor of 10 , and temperature $300 \mathrm{~K}$. The collective variables had hill widths of $0.5 \mathrm{~nm}$ (radius of gyration and distance), and 0.1 (alpha-helical and 310 -helix coordination numbers).

The combination of classical MD with an enhanced sampling scheme promotes the exploration of multiple conformation states of the peptide. However, the prevalence of specific conformations can be over-predicted or under-predicted according to the accuracy of the force field used. ${ }^{76}$ To correct for these inaccuracies and ensure that experimentally relevant conformations are correctly represented in the simulation, we combined the parallel bias enhanced sampling method with metainference. ${ }^{48,49}$ Using Bayesian inference, this approach allows for the NMR chemical shifts to be used as restraints on the predicted chemical shifts averaged over an ensemble of peptide conformations. Chemical shifts were calculated on-the-fly using CAMSHIFT ${ }^{47}$ (as implemented in the PLUMED $2.4{ }^{77}$ library). Our criteria for assessing convergence, and demonstration of convergence of the calculations are discussed in the SI (Figures S8-10).

Validation of Peptide Structures-After the production simulations are completed, the simulation trajectories are analyzed to find the most representative structures of the surfacebound peptide. Since the trajectories are large, every $50^{\text {th }}$ frame is used for analysis, resulting in 20000 frames. Further, some frames were excluded from the trajectory as mentioned in Section 1 in the SI. Finally, the chemical shifts calculated at every frame. Backbone chemical shifts were calculated on the fly using CAMSHIFT ${ }^{47}$ as implemented in PLUMED, whereas side-chain chemical shifts were calculated using SHIFTX ${ }^{46}$ since CAMSHIFT does not provide side chain chemical shifts.

At the end of the simulation, we can use the accumulated bias potential as weights to calculate the free energy with respect to another variable (separate from the variables biased in the original simulation). ${ }^{78} \mathrm{~A}$ weight $\left(=e^{\frac{V}{k T}}\right.$, where $\mathrm{kT}=2.5 \mathrm{~kJ} / \mathrm{mol}$ at $300 \mathrm{~K}, \mathrm{~V}$ is the bias at each frame) is assigned to each frame using the bias potential as a quasi-static bias potential. These weights were used to calculate the weighted average chemical shift from the trajectory, following the protocol of Torrie and Valleau. ${ }^{79}$ The root-mean-squared error of the backbone and side-chain chemical shifts, with reference to the experimentally determined values, were calculated using the formula: 


$$
R M S E=\left(\sum_{i=1}^{N}\left(\mathrm{CS}_{i, \text { predicted }}-\mathrm{CS}_{i, \text { exp }}\right)^{2}\right)^{0.5}
$$

Detection of Top-weighted Peptide Conformations-The structures of the peptide in the trajectory are identified and clustered using the gromos ${ }^{80}$ method (RMSD calculation using alpha-carbon atoms with cut-off of $0.20 \mathrm{~nm}$ ). Then, the cluster number assigned to each frame of the trajectory is reweighted with the above-mentioned weights.

Detection of Top-weighted Peptide Orientations-To study relaxation of the sidechains and orientation of the peptides on the surfaces, the top three weighted conformations for each surface were extracted and simulated for $50 \mathrm{~ns}$ in the NVT ensemble $(300 \mathrm{~K})$. The backbone was held rigid during the simulation using a restraint on the RMSD of the C-alpha carbons using a harmonic restraining potential (Value $=0.15 \mathrm{~nm}$; Kappa $=$ 10000.0). No other bias was added during these simulations. The trajectories were viewed in VMD to identify the residues that interact with each surface (shown in Figure S4-6). For a quantitative analysis of contacting residues, the normal surface distance of side-chain atoms $(\mathrm{C} \gamma, \mathrm{C} \delta, \mathrm{C} \varepsilon$, and $\mathrm{C} \zeta)$ from a reference surface atom was calculated for the whole trajectory. The probability of the occurrence of the side-chain atom at a certain distance from the surface was calculated using the kernel density estimation technique (shown in Figure S7).

Detection of the secondary structure of each residue-A secondary structure was assigned to each residue of SNa15 in each frame of the trajectory using the do_dssp functionality of the GROMACS simulation engine. The probability of each residue being in a certain secondary structure was calculated using the reweighting procedure mentioned above.

\section{Supplementary Material}

Refer to Web version on PubMed Central for supplementary material.

\section{Acknowledgements.}

GPD acknowledges National Institutes of Health Grants RO1-GM109417, GPD and JP acknowledge grants NIH R21 A126113 and National Science Foundation Grant MCB-1715123. This work was facilitated using computational, storage, and networking infrastructure provided by the Hyak supercomputer system, supported in part by the University of Washington and the UW Student Technology Fee Proposal program and NSF MRI program CHE-1624430. GPD also acknowledges support from sub-contract ANSK-0119-16 and helpful conversations with Professors Havard J. Haugen and S. Petter Lyngstadaas of the Department of Biomaterials, Institute for Clinical Chemistry University of Oslo.

\section{References}

(1). Elhadj S; De Yoreo JJ; Hoyer JR; Dove PM Proc. Natl. Acad. Sci. U. S. A 2006, 103 (51), 1923719242. [PubMed: 17158220]

(2). Boskey AL; Maresca M; Ullrich W; Doty SB; Butler WT; Prince CW Bone Miner 1993, 22 (2), 147-159. [PubMed: 8251766]

(3). Shiraga H; Min W; Vandusen WJ; Clayman Ii MD; Miner D; Terrell CH; Sherbotie JR; Foreman JW; Przysiecki C; Neilson EG; Hoyer JR Med. Sci 1992, 89, 426-430. 
(4). Naka K; Chujo Y Chem. Mater 2001, 13 (10), 3245-3259.

(5). Sollner C; Burghammer M; Busch-Nentwich E; Berger J; Schwarz H; Riekel C; Nicolson T Science (80-. ) 2003, 302 (5643), 282-286.

(6). Kröger N; Poulsen N Annu. Rev. Genet 2008, 42, 83-107. [PubMed: 18983255]

(7). Kröger N; Deutzmann R; Bergsdorf C; Sumper M PNAS 2000, 97 (26), 14133-14138. [PubMed: 11106386]

(8). Sumper M; Kröger N J. Mater. Chem 2004, 14, 2059-2065.

(9). Kroger N; Lorenz S; Brunner E; Sumper M Science (80-. ) 2002, 298 (5593), 584-586.

(10). Kröger N; Deutzmann R; Sumper M Science (80-. ) 1999, 286 (5442), 1129-1132.

(11). Weiner S; Addadi L J. Mater. Chem 1997, 7 (5), 689-702.

(12). Goobes G; Goobes R; Shaw WJ; Gibson JM; Long JR; Raghunathan V; Schueler-Furman O; Popham JM; Baker D; Campbell CT; Stayton PS; Drobny GP Magn. Reson. Chem 2007, 45 (S1), S32-S47. [PubMed: 18172904]

(13). DeGrado W; Lear J J. Am. Chem. Soc 1985, 107 (10), 7684-7689.

(14). Masica DL; Gray JJ; Shaw WJ J. Phys. Chem. C 2011, 115, 13775-13785.

(15). Lu J; Burton SD; Xu YS; Buchko GW; Shaw WJ Front. Physiol 2014, 5, 254. [PubMed: 25071599]

(16). Shaw WJ Solid State Nucl. Magn. Reson 2015, 70, 1-14. [PubMed: 25466354]

(17). Shaw WJ; Ferris K; Tarasevich B; Larson JL Biophys. J 2008, 94, 3247-3257. [PubMed: 18192371]

(18). Scudeller LA; Srinivasan S; Rossi AM; Stayton PS; Drobny GP; Castner DG Biointerphases 2017, 12 (2), 02D411.

(19). Masica DL; Ash JT; Ndao M; Drobny GP; Gray JJ Structure 2010, 18, 1678-1687. [PubMed: 21134646]

(20). Gibson JM; Popham JM; Raghunathan V; Stayton PS; Drobny GP J. Am. Chem. Soc 2006, 128, 5364-5370. [PubMed: 16620107]

(21). Gibson JM; Raghunathan V; Popham JM; Stayton PS; Drobny GP J. Am. Chem. Soc 2005, 127, 9350-9351. [PubMed: 15984845]

(22). Makrodimitris K; Masica DL; Kim ET; Gray JJ J. Am. Chem. Soc 2007, 129, 13713-13722. [PubMed: 17929924]

(23). Ndao M; Ash JT; Breen NF; Goobes G; Stayton PS; Drobny GP Langmuir 2009, 25 (20), 1213612143. [PubMed: 19678690]

(24). Weidner T; Dubey M; Breen NF; Ash J; Baio JE; Jaye C; Fischer DA; Drobny GP; Castner DG J. Am. Chem. Soc 2012, 134, 8750-8753. [PubMed: 22563672]

(25). Weidner T; Breen NF; Li K; Drobny GP; Castner DG Proc. Natl. Acad. Sci 2010, 107 (30), 13288-13293. [PubMed: 20628016]

(26). Ndao M; Ash JT; Stayton PS; Drobny GP SUSC 2010, 604, L39-L42.

(27). Li K; Emani PS; Ash J; Groves M; Drobny GP J. Am. Chem. Soc 2014, 136, 11402-11411. [PubMed: 25054469]

(28). Brandt EG; Lyubartsev AP J. Phys. Chem. C 2015, 119, 18126-18139.

(29). Goobes R; Goobes G; Shaw WJ; Drobny GP; Campbell CT; Stayton PS Biochemistry 2007, 46, 4725-4733. [PubMed: 17391007]

(30). Ndao M; Ash JT; Breen NF; Goobes G; Stayton PS; Drobny GP Langmuir 2009, 25 (20), 1213612143. [PubMed: 19678690]

(31). Raj PA; Johnsson M; Levine MJ; NancollasllII GH J. Biol. Chem 1992, 267 (9), 5968-5976. [PubMed: 1313424]

(32). Goobes G; Goobes R; Schueler-Furman O; Baker D; Stayton PS; Drobny GP PNAS 2006, 103 (44), 16083-16088. [PubMed: 17060618]

(33). Long JR; Shaw WJ; Stayton PS; Drobny GP Biochemistry 2001, 40 (51), 15451-15455. [PubMed: 11747419]

(34). Moreno EC; Kresak M; Hay DI Calcif. Tissue Int 1984, 36 (1), 48-59. [PubMed: 6423236]

(35). Elgavish GA; Hay DI; Schlesinger DH Int. J. Pept. Protein Res 1984, 23 (3), 230-234. 
(36). Naganagowda GA; Gururaja TL; Levine MJ J. Biomol. Struct. Dyn 1998, 16 (1), 91-107. [PubMed: 9745898]

(37). Roehrich A; Drobny GP Acc. Chem. Res 2013, 46 (9), 2136-2144. [PubMed: 23932180]

(38). Raghunathan V; Gibson JM; Goobes G; Popham JM; Louie EA; Stayton PS; Drobny GP J. Phys. Chem. B 2006, 110, 9324-9332. [PubMed: 16671751]

(39). Douglas WH; Reeh ES; Ramasubbu N; Raj PA; Bhandary KK; Levine MJ Biochem. Biophys. Res. Commun 1991, 180 (1), 91-97. [PubMed: 1718282]

(40). Shaw WJ; Long JR; Campbell AA; Stayton PS; Drobny GP J. Am. Chem. Soc 2000, 122, 71187119.

(41). Shaw WJ; Long JR; Dindot JL; Campbell AA; Stayton PS; Drobny GP J. Am. Chem. Soc 2000, 122, 1709-1716.

(42). Masica DL; Gray JJ Biophys. J 2009, 96 (8), 3082-3091. [PubMed: 19383454]

(43). Valsson O; Tiwary P; Parrinello M Annu. Rev. Phys. Chem 2016, 67 (1), 159-184. [PubMed: 26980304]

(44). Laio A; Parrinello M Proc. Natl. Acad. Sci. U. S. A 2002, 99 (20), 12562-12566. [PubMed: 12271136]

(45). Deighan M; Pfaendtner J Langmuir 2013, 29 (25), 7999-8009. [PubMed: 23706011]

(46). Neal S; Nip AM; Zhang H; Wishart DS J. Biomol. NMR 2003, 26 (3), 215-240. [PubMed: 12766419]

(47). Kohlhoff KJ; Robustelli P; Cavalli A; Salvatella X; Vendruscolo M J. Am. Chem. Soc 2009, 131 (39), 13894-13895. [PubMed: 19739624]

(48). Bonomi M; Camilloni C; Vendruscolo M Sci. Rep 2016, 6 (1), 31232. [PubMed: 27561930]

(49). Bonomi M; Camilloni C; Cavalli A; Vendruscolo M Sci. Adv 2016, 2 (1), e1501177. [PubMed: 26844300]

(50). Bonomi M; Camilloni C Bioinformatics 2017, 33 (24), 3999-4000. [PubMed: 28961689]

(51). Raiteri P; Laio A; Gervasio FL; Micheletti C; Parrinello M J. Phys. Chem. B 2006, 110 (8), 3533-3539. [PubMed: 16494409]

(52). Shen Y; Bax A J. Biomol NMR 2013, 56 (3), 227-241. [PubMed: 23728592]

(53). Robustelli P; Kohlhoff K; Cavalli A; Vendruscolo M Structure 2010, 18 (8), 923-933. [PubMed: 20696393]

(54). Boehr DD; Nussinov R; Wright PE Nature Chemical Biology Nature Publishing Group 112009 , pp 789-796.

(55). Fernandez VL; Reimer JA; Denn MM J. Am. Chem. Soc 1992, 114, 9634-9642.

(56). Pettersen EF; Goddard TD; Huang CC; Couch GS; Greenblatt DM; Meng EC; Ferrin TE J. Comput. Chem 2004, 25 (13), 1605-1612. [PubMed: 15264254]

(57). Koutsopoulos S; Dalas E Langmuir 2000, 16, 6739-6744.

(58). Buckle EL; Lum JS; Roehrich A; Stote RE; Dracinsky M; Filocamo SF; Drobny GP J. Phys. Chem. B 2018.

(59). Morcombe CR; Zilm KW J. Magn. Reson 2003, 162 (2), 479-486. [PubMed: 12810033]

(60). Bertani P; Raya J; Bechinger B Solid State Nucl. Magn. Reson 2014, 61-62, 15-18.

(61). Lindorff-Larsen K; Piana S; Palmo K; Maragakis P; Klepeis JL; Dror RO; Shaw DE Proteins Struct. Funct. Bioinforma 2010, 78 (8), NA-NA.

(62). Perera L; Berkowitz ML J. Chem. Phys 1991, 95 (3), 1954.

(63). Heinz H; Lin T-J; Kishore Mishra R; Emami FS Langmuir 2013, 29 (6), 1754-1765. [PubMed: 23276161]

(64). Předota M; Bandura AV; Cummings PT; Kubicki JD; Wesolowski DJ; Chialvo AA; Machesky ML J. Phys. Chem. B 2004, 108 (32), 12049-12060.

(65). Sprenger KG; Prakash A; Drobny G; Pfaendtner J Langmuir 2018, 34, 1199-1207. [PubMed: 28981294]

(66). Prakash A; Sprenger KG; Pfaendtner J Biochem. Biophys. Res. Commun 2017, 498 (2), 274 281. [PubMed: 28720500] 
(67). Emami FS; Puddu V; Berry RJ; Varshney V; Patwardhan SV; Perry CC; Heinz H Chem. Mater 2014, 26 (19), 5725-5734.

(68). Heinz H Curr. Opin. Chem. Eng 2016, 11, 34-41.

(69). Wu C; Chen M; Xing C Langmuir 2010, 26 (20), 15972-15981. [PubMed: 20857968]

(70). Berendsen HJC; Postma JPM; Van Gunsteren WF; Dinola A; Haak JR J. Chem. Phys 1984, 81 (8), 3684-3690.

(71). Bussi G; Donadio D; Parrinello M J. Chem. Phys 2007, 126 (1), 014101. [PubMed: 17212484]

(72). Darden T; York D; Pedersen L J. Chem. Phys 1993, 98 (12), 10089-10092.

(73). Hess B; Bekker H; Berendsen HJC; Fraaije JG E. M J. Comput. Chem 1997, 18 (12), 1463-1472.

(74). Abraham MJ; Murtola T; Schulz R; Páll S; Smith JC; Hess B; Lindah E SoftwareX 2015, 1-2, $19-25$.

(75). Pfaendtner J; Bonomi M J. Chem. Theory Comput 2015, 11 (11), 5062-5067. [PubMed: 26574304]

(76). Hornak V; Abel R; Okur A; Strockbine B; Roitberg A; Simmerling C Proteins Struct. Funct. Bioinforma 2006, 65 (3), 712-725.

(77). Tribello GA; Bonomi M; Branduardi D; Camilloni C; Bussi G Comput. Phys. Commun 2014, 185 (2), 604-613.

(78). Prakash A; Fu CD; Bonomi M; Pfaendtner JJ Chem. Theory Comput 2018, acs.jctc.8b00448.

(79). Torrie GM; Valleau JP J. Comput. Phys 1977, 23 (2), 187-199.

(80). Daura X; Gademann K; Jaun B; Seebach D; van Gunsteren WF; Mark AE Angew. Chemie Int. Ed 1999, 38 (1-2), 236-240.

(81). Chen P-H; Tseng Y_H; Mou Y; Tsai Y-L, Guo S-M; Huang S-J; Yu S; Chan J J. Amer. Chem. Soc 2008, 130, 2862-2868. [PubMed: 18266360]

(82). Santos O; Kosoric J; Hector MP; Anderson P; Lindh LJ Coll. Interf. Sci 2008, 318, 175-182.

(83). Wilson CJ, Clegg RE, Leavesley DI \& Pearcy MJ. Tissue Eng 2005 11, 1-18. [PubMed: 15738657]

(84). Jones FH Surf. Sci. Rep 2001 42, 75-205.

(85). Macdonald DE, Deo N, Markovic B, Stranick M \& Somasundaran P Biomaterials 2002 23, 1269-1279. [PubMed: 11791930]

(86). Verket A; Tiainin H; Haugen H; Lyngstadaas SP, Nilsen O, Reseland JE Biointerphases 2012, 7:36. [PubMed: 22623280] 
(a)

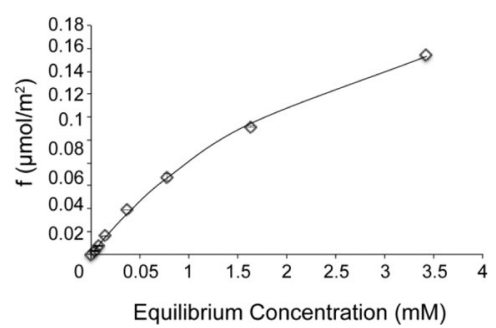

(b)

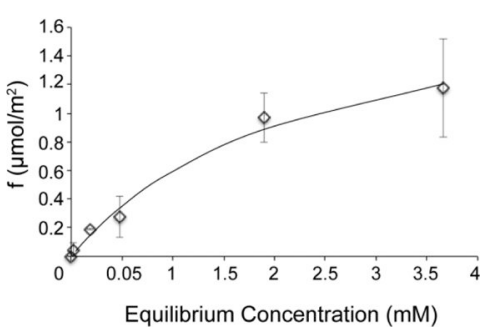

Figure 1.

Adsorption isotherms for SNa15 interacting with (a) $\mathrm{SiO}_{2}$ and (b) $\mathrm{TiO}_{2}$. Data are a mean from two independent repeats, and the standard deviation is shown. The disassociation constants obtained from the fitting are: $\mathrm{K}_{\mathrm{d}}=2.98 \mathrm{mM}$ for $\mathrm{SiO}_{2}$ and $\mathrm{K}_{\mathrm{d}}=2.30 \mathrm{mM}$ for $\mathrm{TiO}_{2}$. 


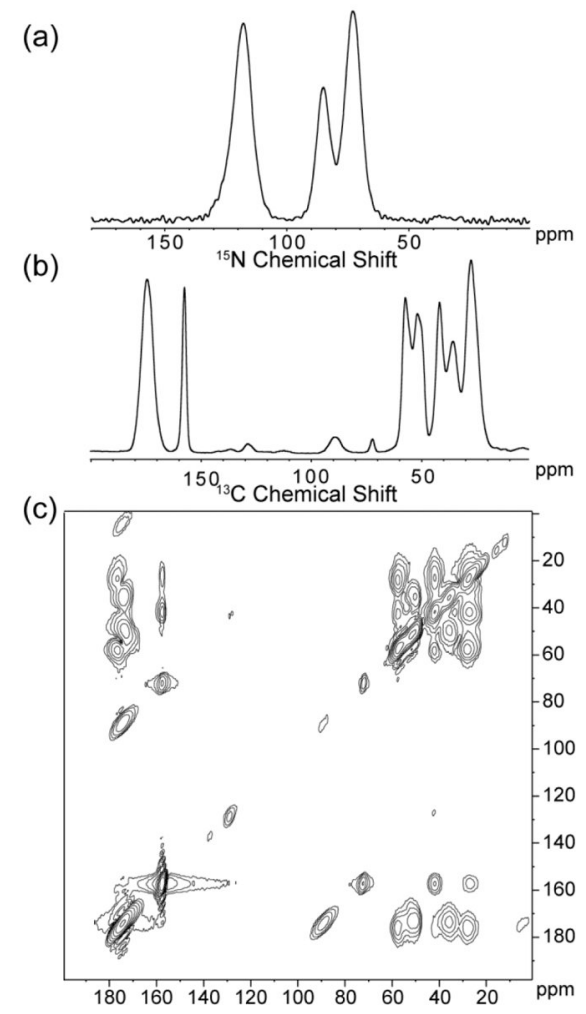

Figure 2.

Representative set of the data collected for each labeled SNa15 peptide in each of the studied phases: neat and adsorbed on $\mathrm{HAP}, \mathrm{SiO}_{2}$, and $\mathrm{TiO}_{2}$. The data shown are for D2R9 and are the following: (a) ${ }^{15} \mathrm{~N} \mathrm{CP}$ MAS, (b) ${ }^{13} \mathrm{C} \mathrm{CP}$ MAS, and (c) ${ }^{13} \mathrm{C}-{ }^{13} \mathrm{C}$ DARR. 
(a)

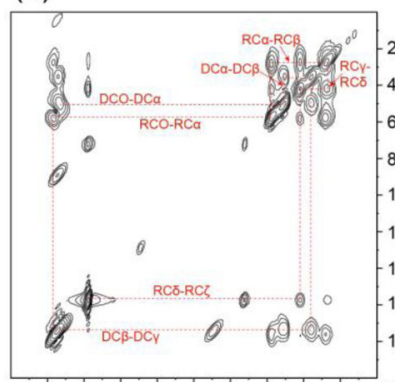

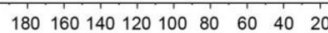

(d)

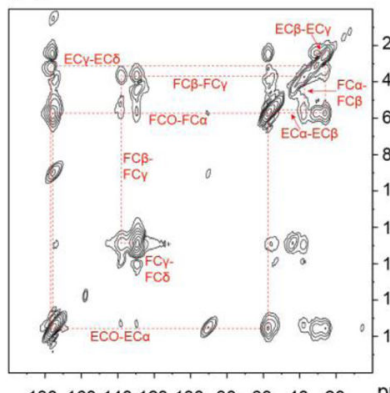

(b)

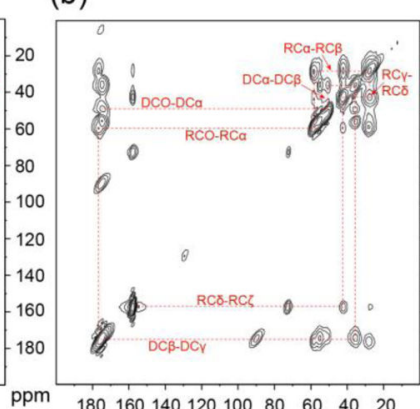

(e) (c)

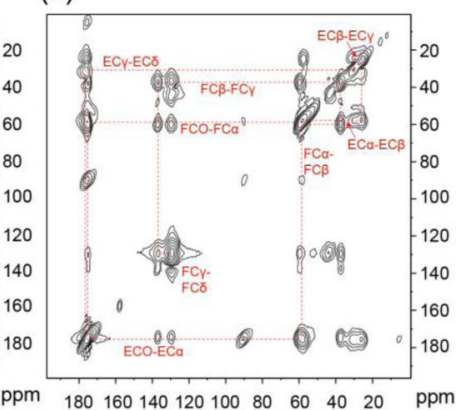

$18016014012010080 \quad 60 \quad 40 \quad 20$

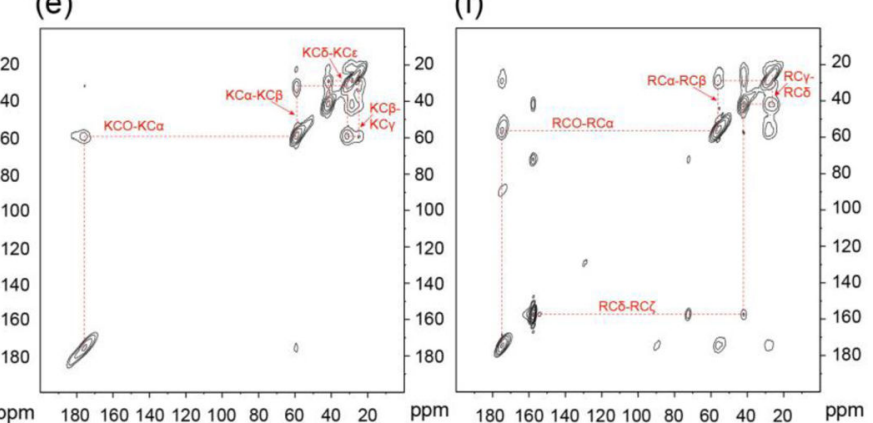

Figure 3.

${ }^{13} \mathrm{C}-{ }^{13} \mathrm{C}$ DARR spectra of neat (a) D2R9, (b) D3R10, (c) E4F7, (d) E5F14, (e) K6, and (f) $\mathrm{R} 13$. The dashed lines show the correlation of spins. 


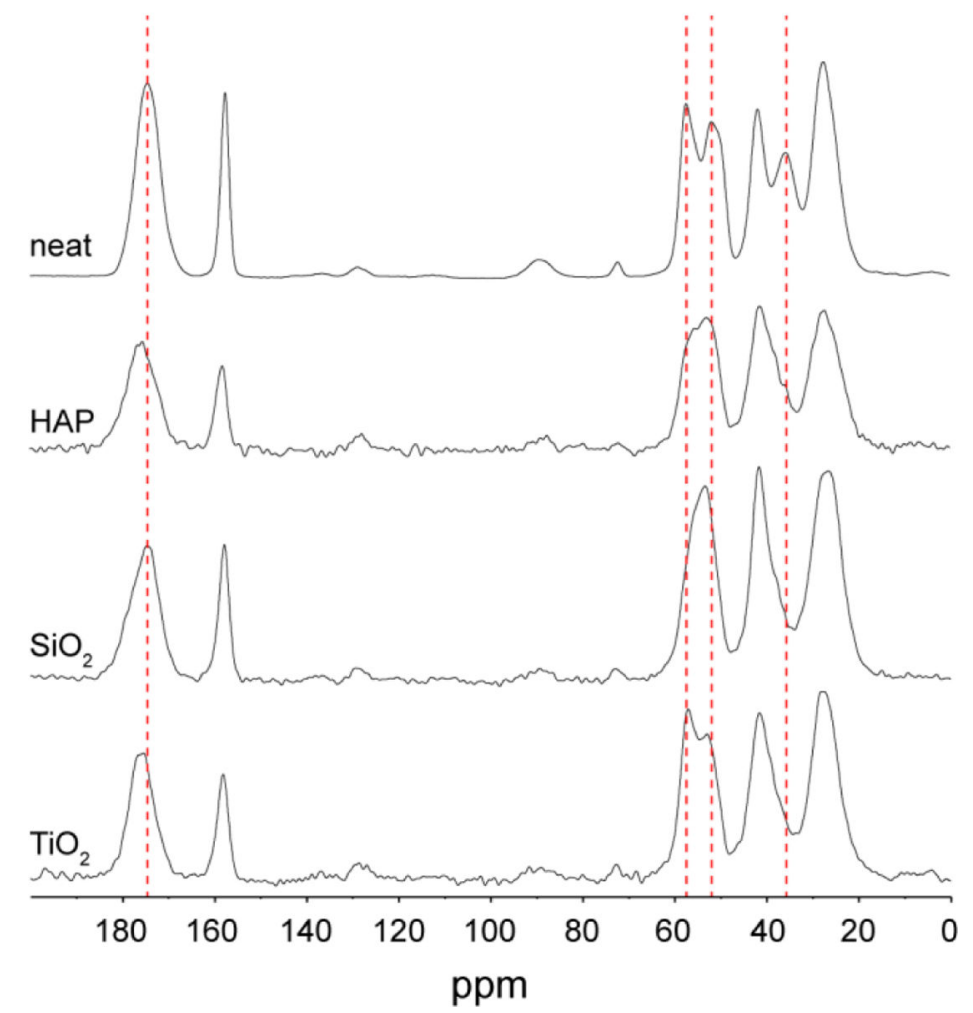

Figure 4.

${ }^{13} \mathrm{C} \mathrm{CP}$ MAS spectra of D2R9 in four phases: neat, adsorbed to $\mathrm{HAP}$, adsorbed to $\mathrm{SiO}_{2}$, and adsorbed to $\mathrm{TiO}_{2}$. The dashed lines highlight some of the more obvious chemical shift differences between the four spectra. 
(a) $\quad \mathrm{CO}$

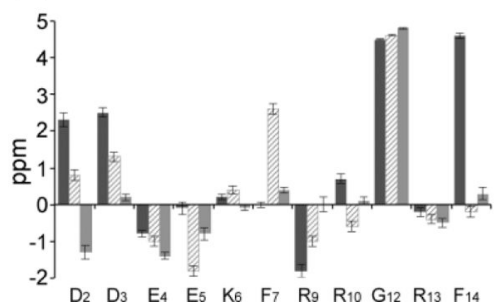

(b)

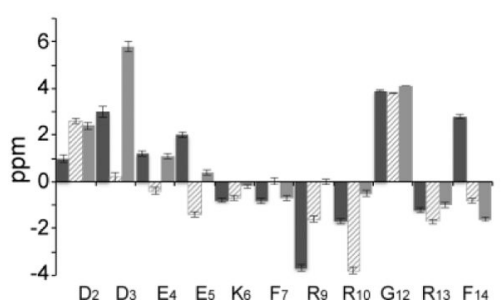

(c)

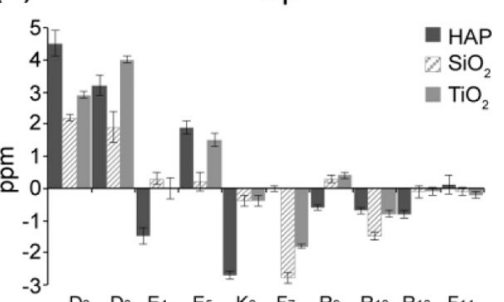

Figure 5.

Backbone $\Delta \mathrm{CS}$ plots showing chemical shift perturbations for (a) ${ }^{13} \mathrm{CO}$ shifts, (b) ${ }^{13} \mathrm{Ca}$ shifts, and (c) ${ }^{13} \mathrm{C} \beta$ shifts. $\Delta \mathrm{CS}$ for $\mathrm{SNa} 15$ on $\mathrm{HAP}$ (black), $\mathrm{SiO}_{2}$ (hatched), and $\mathrm{TiO}_{2}$ (gray) are in reference to neat $\mathrm{SNa} 15$. Positive changes indicate a downfield shift while negative changes indicate an upfield shift relative to the neat peptide. 

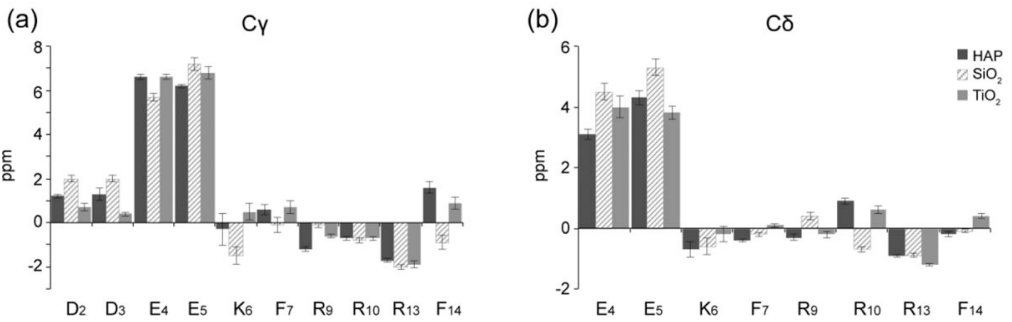

(c)

$\mathrm{C \varepsilon}$

(d)

$c \zeta$
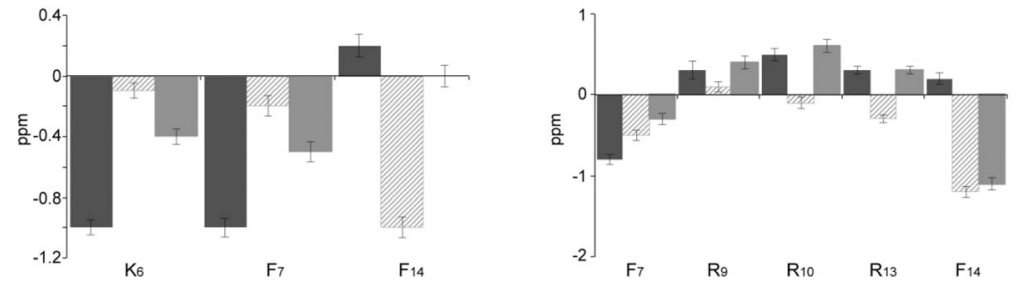

Figure 6.

Side-chain $\Delta \mathrm{CS}$ plots showing chemical shift perturbations for (a) ${ }^{13} \mathrm{C} \gamma$ shifts, (b) ${ }^{13} \mathrm{C} \delta$ shifts, (c) ${ }^{13} \mathrm{C} \varepsilon$ shifts, and (d) ${ }^{13} \mathrm{C} \zeta \Delta \mathrm{CS}$. $\Delta \mathrm{CS}$ for SNa15 on HAP (black), $\mathrm{SiO}_{2}$ (hatched), and $\mathrm{TiO}_{2}$ (gray) are in reference to neat $\mathrm{SNa} 15$. Positive changes indicate a downfield shift while negative changes indicate an upfield shift relative to the neat peptide. 
(a)

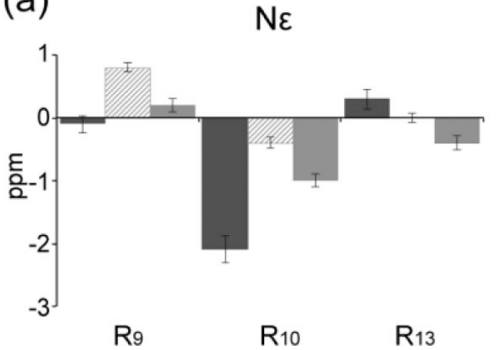

(b)

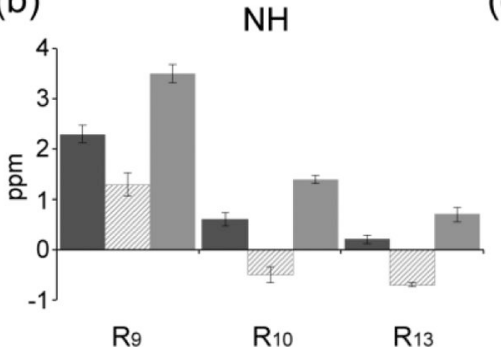

(c)

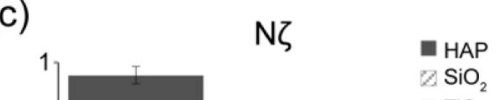

$\because \mathrm{TiO}_{2}$

Figure 7.

Side-chain $\triangle$ CS plots showing chemical shift perturbations for (a) ${ }^{15} \mathrm{~N} \varepsilon$, (b) ${ }^{15} \mathrm{NH}$, and (c) ${ }^{15} \mathrm{~N} \zeta$. $\Delta \mathrm{CS}$ for $\mathrm{SNa} 15$ on HAP (black), $\mathrm{SiO}_{2}$ (hatched), and $\mathrm{TiO}_{2}$ (gray) are in reference to neat SNa15. Positive changes indicate a downfield shift while negative changes indicate an upfield shift relative to the neat peptide. 

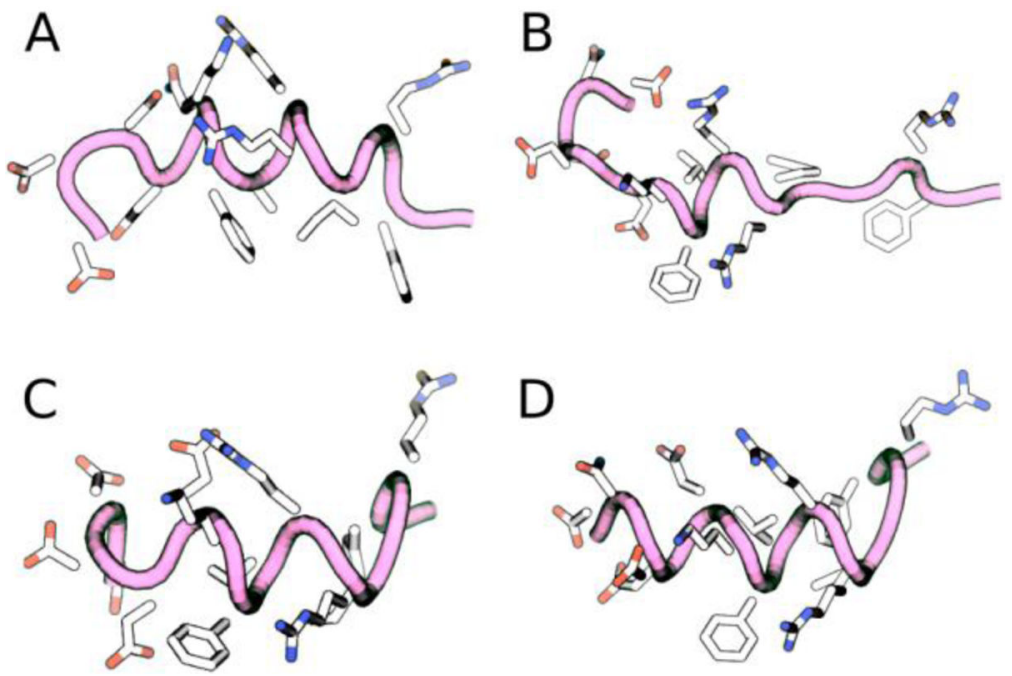

Figure 8.

Chimera ${ }^{56}$-generated models of (a) SNa15-neat, (b) $\mathrm{SNa}$ - $-\mathrm{SiO}_{2}$, (c) SNA15-HAP, and (d) $\mathrm{SNa} 15-\mathrm{TiO}_{2}$ using TALOS- $\mathrm{N}^{52}$-predicted torsion angles from experimentally obtained chemical shifts. Each peptide is shown from $\mathrm{N}$-terminus to $\mathrm{C}$-terminus right-to-left. 

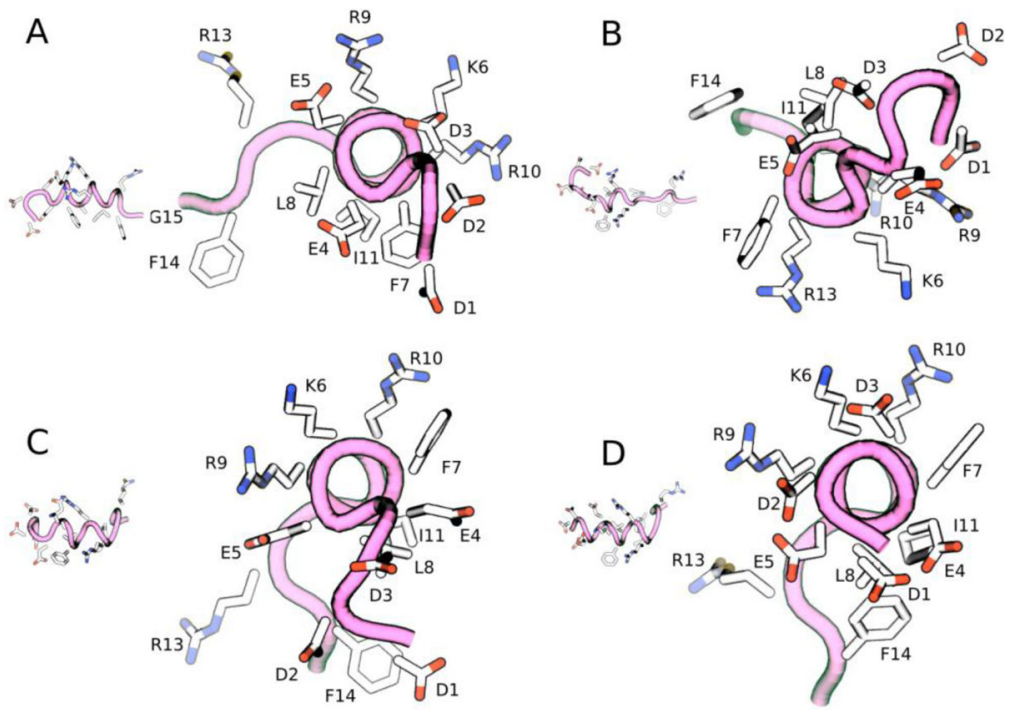

Figure 9.

End-view of (a) SNa15-neat, (b) SNa15-SiO2, (c) SNA15-HAP, and (d) $\mathrm{SNa}^{2}$ - $-\mathrm{TiO}_{2}$ with each residue labeled. Structures are visualized with Chimera ${ }^{56}$ using torsion angles predicted by TALOS-N. ${ }^{52}$ 


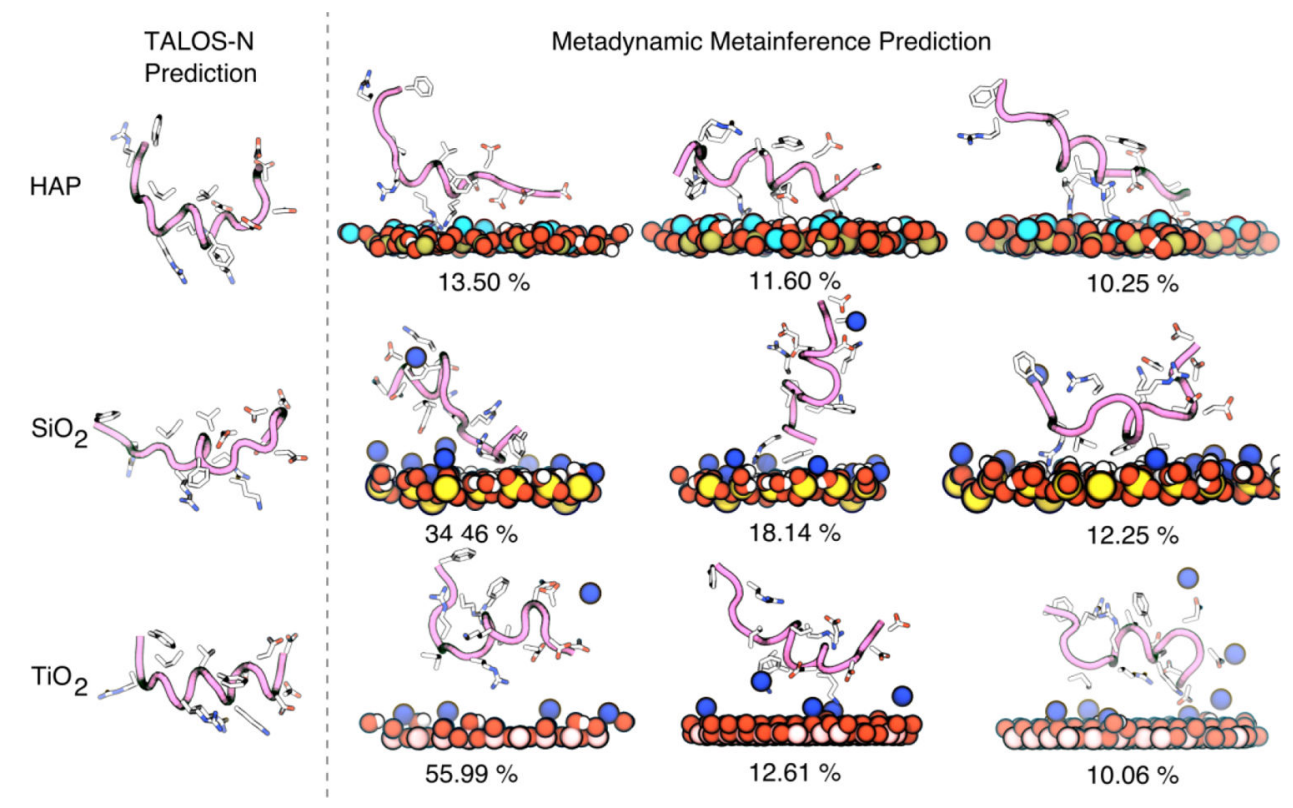

Figure 10.

TALOS-N prediction and metadynamics metainference predictions of the structures of $\mathrm{SNa} 15$ on HAP (top), $\mathrm{SiO}_{2}$ (center), and $\mathrm{TiO}_{2}$ (bottom) surfaces. The peptide backbone is shown in mauve with tube structure. Surface atoms are colored blue for sodium ions, light blue for calcium, red for oxygen, yellow for silicon. The heavy side-chain atoms on the protein are rendered with licorice and colored blue for nitrogen, red for oxygen, and white for carbon. The percentages of the MD configurations refer to the weight of that cluster within the structural ensemble. 


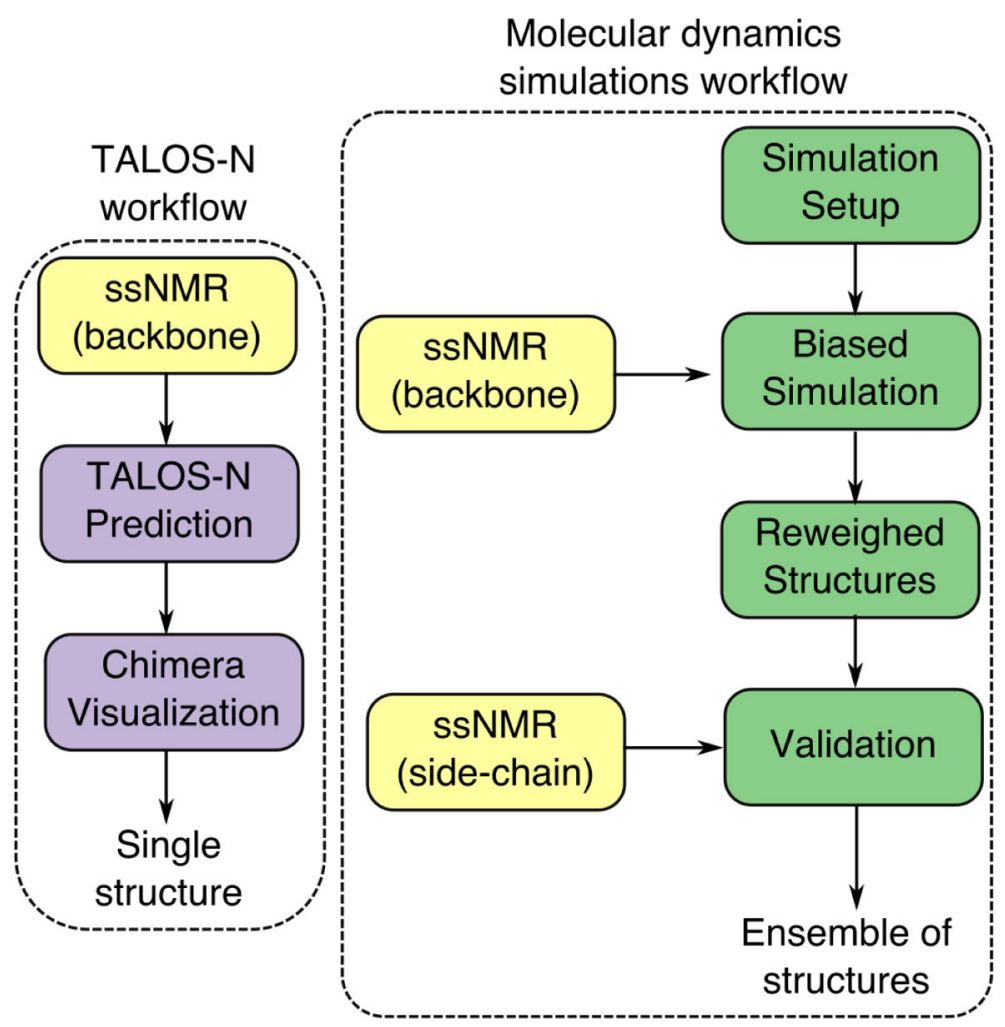

Scheme 1.

Schematic of the modeling and simulation workflows used in this study 
Table 1.

SNa15 peptides synthesized in this study. (*) Indicates that the preceding amino acid is uniformly ${ }^{13} \mathrm{C}$ and ${ }^{15} \mathrm{~N}$ enriched.

\begin{tabular}{ll}
\hline Sample Name & Label Position \\
D2R9 & DD*DEEKFLR*RIGRFG \\
D3R10 & DDD*EEKFLRR*IGRFG \\
E4F7 & DDDE*EKF*LRRIGRFG \\
E5F14 & DDDEE*KFLRRIGRF*G \\
K6 & DDDEEK*FLRRIGRFG \\
G12 & DDDEEKFLRRIG*RFG \\
R13 & DDDEEKFLRRIGR*FG \\
\hline
\end{tabular}


Table 2.

The root-mean squared error of the backbone and side-chain.

\begin{tabular}{lll}
\hline Simulation & RMSE of backbone & RMSE of side-chains \\
SNa15-HAP & 2.17 & 1.59 \\
SNa15-SiO2 & 2.25 & 1.75 \\
SNa15-TiO2 & 1.91 & 1.48 \\
\hline
\end{tabular}

